Document downloaded from:

http://hdl.handle.net/10251/51289

This paper must be cited as:

Valencia Salazar, I.; Ȧlvarez Bel, CM.; Escrivá Escrivá, G.; Alcázar Ortega, M. (2011). Simulation of demand side participation in Spanish short term electricity markets. Energy Conversion and Management. 52(7):2705-2711. doi:10.1016/j.enconman.2011.02.005.

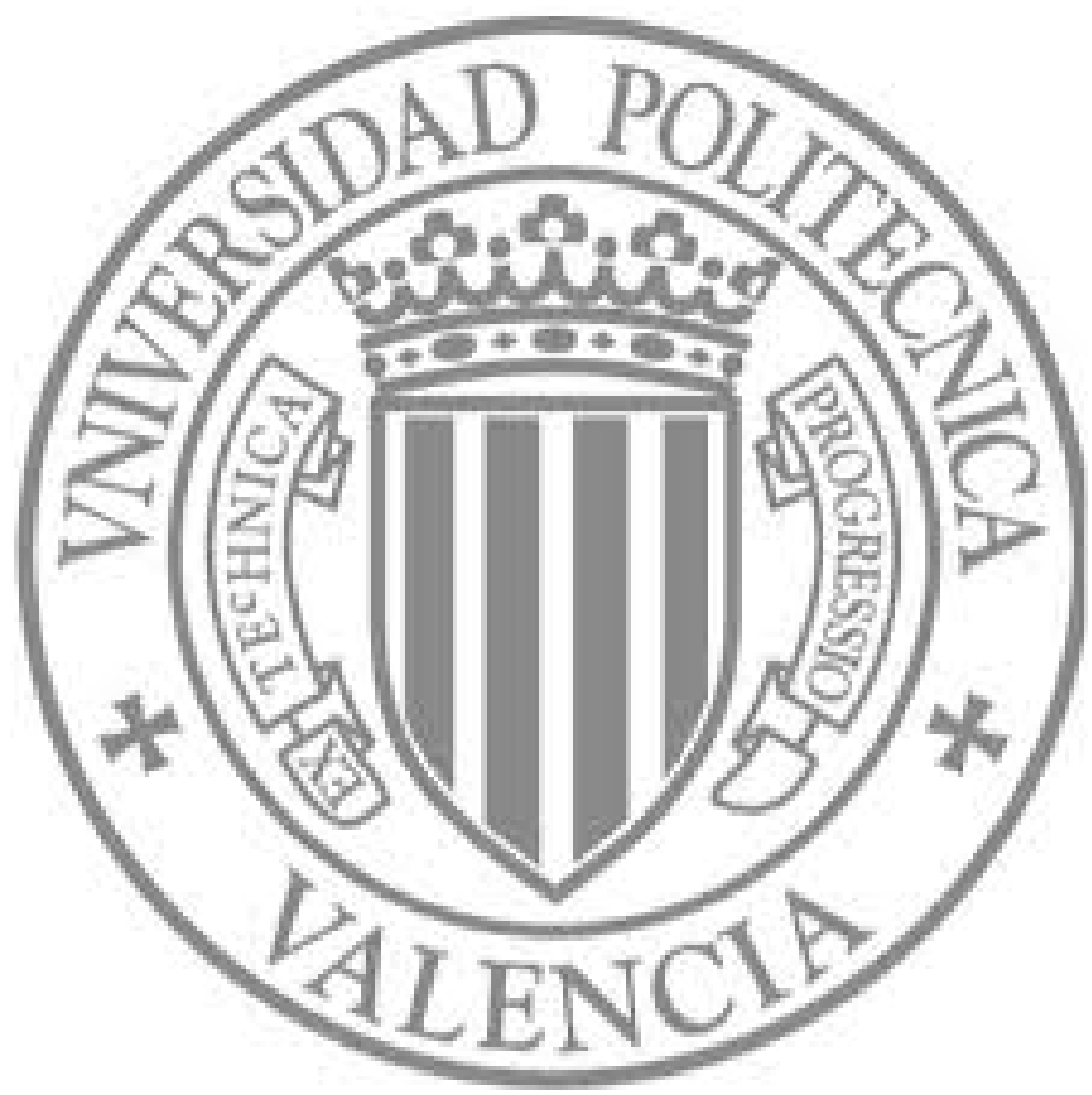

The final publication is available at

http://dx.doi.org/10.1016/j.enconman.2011.02.005

Copyright Elsevier 


\title{
SIMULATION OF DEMAND SIDE PARTICIPATION IN SPANISH SHORT TERM ELECTRICITY MARKETS
}

\author{
I. Valencia-Salazar $\left({ }^{a}\right)$, G. Escrivá-Escrivá $\left({ }^{a}\right)\left({ }^{1}\right)$, M. Alcázar-Ortega $\left({ }^{a}\right)$, C. Álvarez $\left({ }^{a}\right)$
}

${ }^{\left({ }^{a}\right)}$ Institute for Energy Engineering, Universidad Politécnica de Valencia, Camino de Vera, s/n, edificio 8E, escalera $\mathrm{F}, 2^{\mathrm{a}}$ planta. 46022 Valencia, Spain

\begin{abstract}
Demand response resources management is one of the most investigated solutions oriented to improve the efficiency in electricity markets. In this paper, the capability of customers to participate in short term markets is analyzed. An available methodology to analyze the daily and monthly energy consumptions of large customers is used to create energy offers and bids. This allows customers to participate in energy markets in order to buy, as first step, the usual electricity consumption and, additionally, to offer demand reductions in the short term electricity markets. Additionally, this paper shows the customer potential to participate in the Spanish electricity markets.
\end{abstract}

Keywords: Demand response resources; demand modelling; electricity markets; balancing services; ancillary services.

\section{Introduction}

The use of demand resources (DR) is one effective action to improve the performance of deregulated electricity markets. Active demand side participation can reduce the market power of large utilities [1], minimize the network's congestions [2], and produce a better operation in these markets [3, 4]. Cultural, institutional and regulatory barriers [5] to implement or develop demand resources have not impeded that, in the world, several demand response programs have been implemented, or were in progress, [6-12]. Nevertheless many of this programs offer

\footnotetext{
${ }^{1}$ Corresponding author: Tel. +34 963879 240; Fax: +34 963877 272. E-mail address: guieses@die.upv.es
} 
payments to large customers for load reductions, calculated from an expected consumption called 'baseline consumption level' (BCL). This fact introduces a clear market inefficiency that comes into an inefficient system as well [13], because participants are paid for something that they do not have, getting a double payment for the same thing and, sometimes, some programs need to be subsidized.

For this reason, large electricity customers and energy traders may participate buying energy through bids in forward markets (day ahead and/or intra-daily). After this energy transaction is somehow firm, they may participate in short term markets just as generators do, by selling some of the energy previously bought by offering reductions in balance or other ancillary services markets. Due to technological reasons, small and residential consumers are not usually allowed to participate directly in markets [14], but they could participate by managed aggregators in a similar way.

The authors proposed in a previous paper [15] a way to organize the electricity consumption based on physical processes, by taking into account its size, provided service and flexibility. That paper described a methodology developed for the characterization of a large customer in winter and summer.

The objective of the present paper is to extend the proposed concepts in order to estimate the potential participation of large customers in short term markets. A simulation of the participation of a specific customer (a university campus) in the Spanish market (balancing and ancillary services) is performed in order to describe a detailed economic balance of the energy purchases and sales in a real environment.

The paper is organized as follows: In the section 2, a proposed methodology faced to organize the customer demand is used in combination with real tests to settle the basis for the demand description, with the aim of obtaining bids and offers suited for participation in electricity markets for a period of 24 hours. After that, in section 3, the possible target markets in Spain are described. Section 4 is devoted to simulate the participation of this customer in balancing markets, where the possible benefits for the customer are calculated. Finally, some conclusions are drawn in the last section. 


\section{Load characterization and generation of bids and offers}

\subsection{Background}

The authors analyzed in [15] the summer and winter peak of demand in the Universidad Politécnica de Valencia (UPV), produced in January and July. After this characterization, demand bids for energy trading (DSB, amount of energy and price) were identified, as shown in Table 1.

Table 1. Demand bids for UPV

\begin{tabular}{ll} 
Demand Bids (Price) & Description \\
\hline $\begin{array}{l}\text { L1 - 0.50€/kWh } \\
\text { Air Conditioning }\end{array}$ & $\begin{array}{l}\text { Space heating in winter } \\
\text { Space cooling in summer } \\
\text { Characteristic values: }\end{array}$ \\
$\begin{array}{l}\text { L2 - 1€/kWh } \\
\text { Outdoor lighting }\end{array}$ & $\begin{array}{l}\text { January: } 350 \mathrm{~kW} \text { from 18:00 to } 7: 45 \\
\text { J3 }- \text { Indoor lighting: }\end{array}$ \\
$\begin{array}{l}\text { L3a=3€/kWh) } \\
\text { L3b=1€/kWh) }\end{array}$ & L3a: Essential loads to reach an acceptable illumination level \\
L4 - 3€/kWh & Teaching and research loads, electronic equipment, and others \\
Rest of the load &
\end{tabular}

Once bids were obtained, demand offers (DSO, amount of power that the customer is willing to reduce for a payment) were built by using a non-critical load. Different electricity consumption processes were grouped and prices were assigned to each group. The identified demand offers are shown in Table 2.

Table 2. Demand offers for UPV

Demand Offers (Price)

L1a-0.10€/kWh

L1b-0.20€/kWh

$\mathrm{L} 2 \mathrm{~b}-0.30 € / \mathrm{kWh}$

L3b-0.40€/kWh

\section{Description} AC loads that can be interrupted with an average increment in the internal temperature not higher than $2^{\circ} \mathrm{C}$ AC loads will probably produce an average increment in the internal temperature of $4{ }^{\circ} \mathrm{C}$ Interruptible outdoor illumination loads Non-essential indoor illumination 


\subsection{Monthly consumption characterization}

Currently the UPV has got an energy management and control system called DERD [16], which provides information about energy consumed by the different end uses and makes it feasible to control (automatic or manual) the different loads in buildings (air conditioning, indoor and outdoor lighting, pumps, and others). For example, Figure 1 shows the effect of a demand reduction on peak hours in the space heating load curve in a building. In this case the reduction is maintained only for a few minutes, but this action could be longer and combined with other reductions in different buildings.

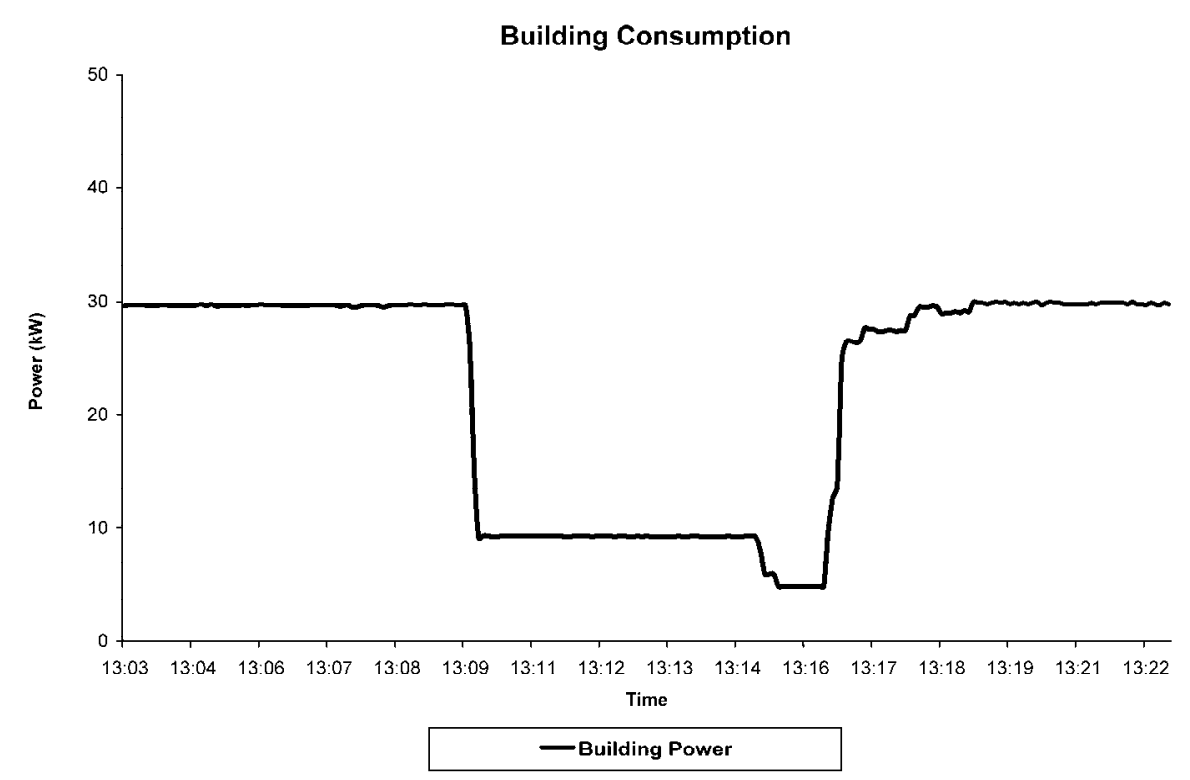

Figure 1. Example of load interruption controlled whit DERD

Concepts reviewed above have been used in this research together with the information provided by the system DERD. The whole information received is used to make new simulations in order to characterize the consumption of the university in the required horizon of time to plan the participation in market. Consequently, demand packages (DPs) used to produce DSB and DSO have been computed for a period of 24 hours.

The potential of the UPV participation in short term markets is evaluated on the January and July peaking months. Firstly, a decomposition of the average load shape for January and July in DPs is obtained, as shown in Figure 2. 

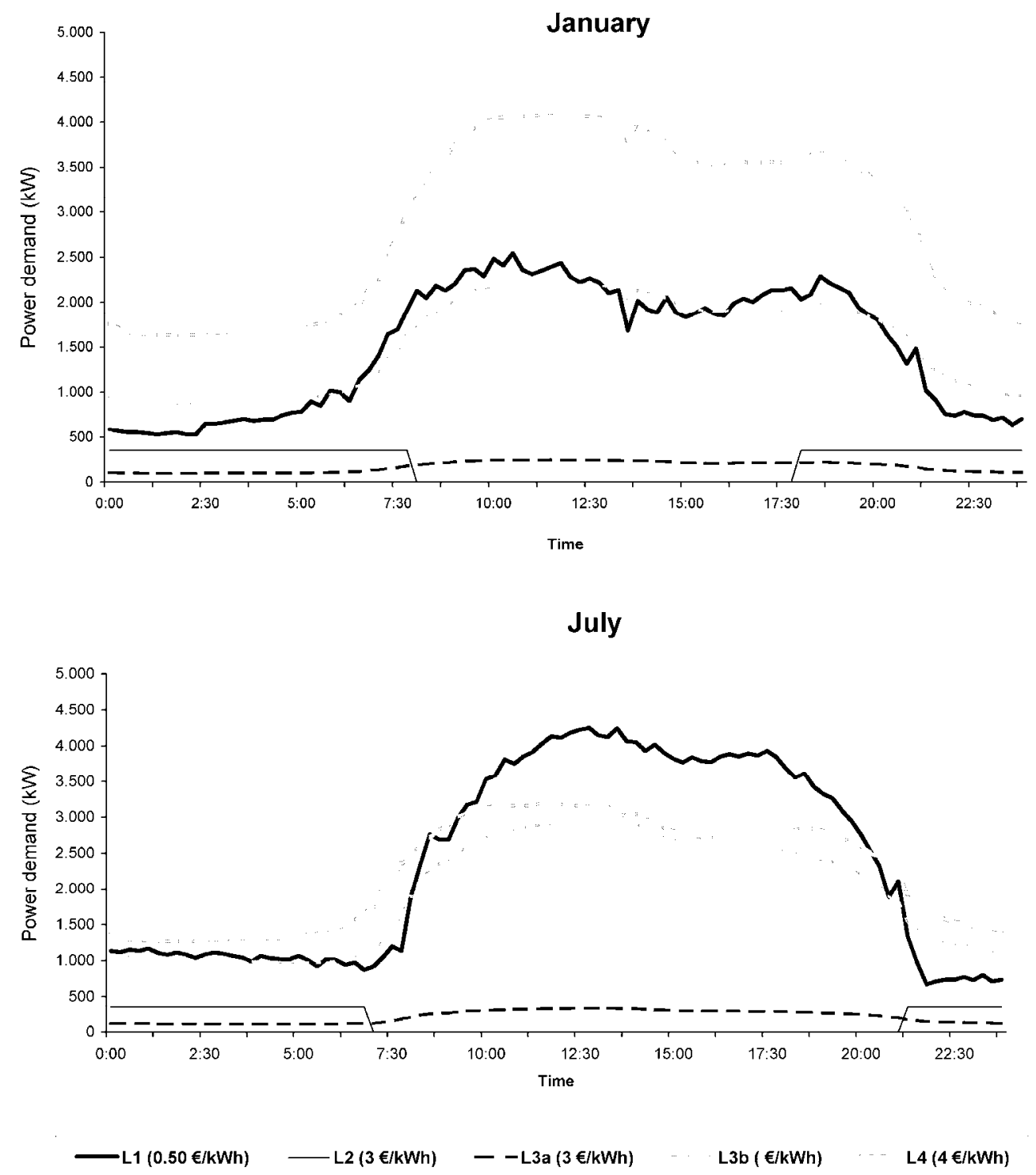

Figure 2. Decomposition of the average load shape in DPs

In order to validate this decomposition, the load curve of each identified end use is added to obtain the total profile of the whole system. After that, this curve is compared with the average load curve measured in January and July, as shown in Figure 3. 


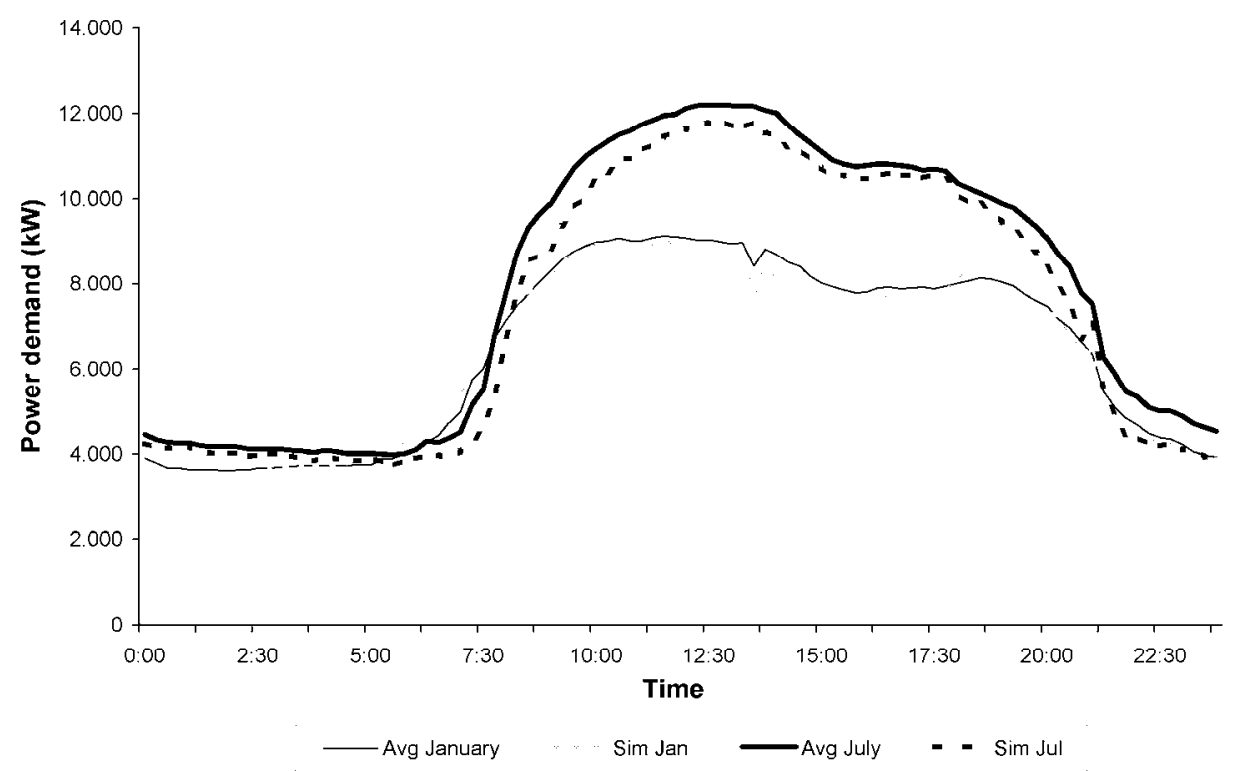

Figure 3. Validation of demand decomposition in DPs

The process of making demand offers to participate in short term markets (from a few hours to 15 minutes ahead) is based on the capability of the consumer to reduce its electricity consumption according to the energy purchased in long term markets through the bidding process.

Coming back to the example, the amounts of power for L1a and L1b DPs are calculated by using physically-based modelling [17], taking into account the expected degradation in the provided service (dwelling internal temperature). In addition, it is necessary to obtain, in a similar way, demand reductions for $L 2 b$ and $L 3 b$. The total interruption of the AC load is not acceptable for the customer, so this condition is not considered in the study.

Secondly, the price of each package is computed by considering the impact of the expected loss of comfort and the cost of the equipment to implement the required control. Figure 4 shows the DSOs and their prices for the UPV. 

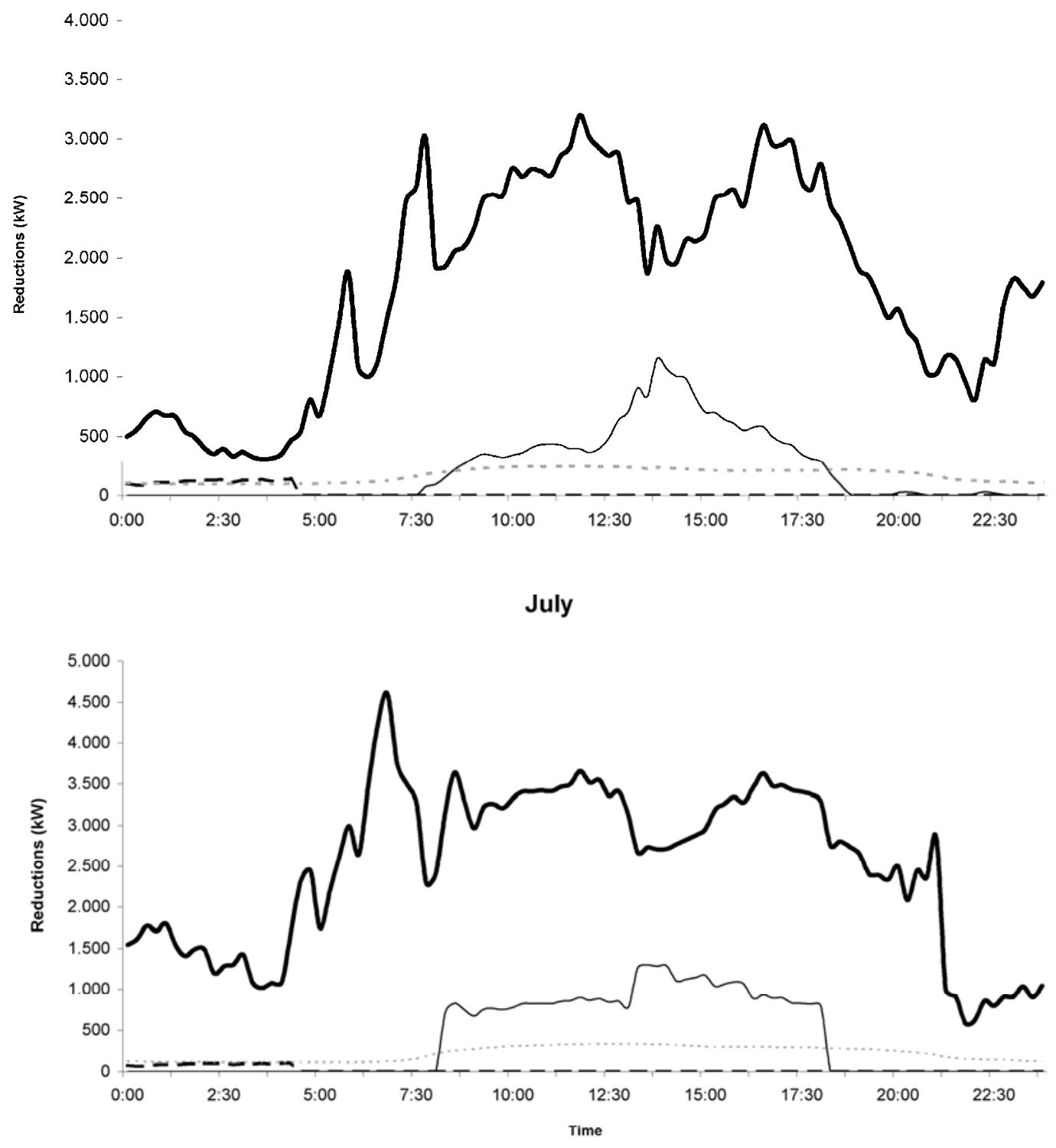

$-\mathrm{L} 1 \mathrm{a}(0.10 € / \mathrm{kWh})-\mathrm{L} 1 \mathrm{~b}(0.20 \epsilon / \mathrm{kWh})--\mathrm{L} 2 \mathrm{~b}(0.3 \epsilon / \mathrm{kWh}) \cdots \operatorname{L3b}(0.4 \epsilon / \mathrm{kWh})$

Figure 4. Average monthly reductions to build offers

The critical issue of the time in which the load reduction has to be implemented (less than 15 minutes) is solved by the control system DERD, which means the UPV campus is technically able to participate in short term markets like balancing or ancillary services markets. The impact of this technical requirement has been validated by using detailed physically-based models, as shown in [17]. It is important to point out that DERD mitigates the recovery peak effect after the 
reduced load has been reconnected, since the time in that these loads are re-switched on might be staggered.

\section{Spanish electricity market structures}

This section aims to discuss about the demand potential participation in the Spanish electricity market structures, so a brief description of this particular market is provided.

In July 2006, the Spanish and Portuguese Electric Markets were fused. Currently, they operate together like MIBEL (Iberian Electricity Market). MIBEL is divided into two different pools:

- A spot market, organized in a day-ahead market (DAM) and several intra-daily market sessions (IDM).

- A long-term market, based on the negotiation of bilateral contracts.

Ancillary services and technical restrictions are managed by the transmission system operators (SO), which are different for each country. For the case of Spain demand is only allowed to participate in DAM and IDM sessions. Additionally, the Spanish SO signs contracts with large customers to participate in interruptibility programs, although amounts of $5 \mathrm{MW}$ are required as minimum interruptible power to participate in this service.

Performing energy transactions for the next day is the purpose of DAM. Market agents participate by presenting energy bids or offers to the market operator $(\mathrm{MO})$ between 8:30 and 10:00. The MO matches the different offers and it determines the marginal price and the volume of energy accepted for each hour in the following day. These matched energy transactions are reviewed by the SO in order to check the possible technical constrains.

The IDM is also managed by the MO. It is a market for adjustments in generation or demand deviations which can take place after the DAM closure. This market consists on six sessions where agents that have previously participated in the DAM can present some new energy offers and bids. The plan of transactions from each intra-daily market is analyzed by the SO.

The SO is also responsible of the operation of both the ancillary services markets (AS) and balancing market (BM) [6], whose purpose is to balance in real time the electricity demand and generation. The BM is activated when deviations higher than $300 \mathrm{MW}$ between the scheduled production (resulting from the last IDM session) and load are detected. 
Table 3 shows the main technical requirements of the different electricity markets, as well as the possibility that Spanish customers have to participate nowadays.

Table 3. Spanish markets requirements and demand participation

\begin{tabular}{llll} 
Type of market & Markets or services & Technical requirements & $\begin{array}{l}\text { Demand can } \\
\text { participate? }\end{array}$ \\
\hline $\begin{array}{l}\text { Day-ahead } \\
\text { Hourly-ahead }\end{array}$ & $\begin{array}{l}\text { Day-ahead market } \\
\text { Intra-daily market }\end{array}$ & - & Yes \\
Balancing market & Deviation Management & Response in 15 min. & Yes \\
$\begin{array}{l}\text { Ancillary services- } \\
\text { frequency control } \\
\text { and reserves }\end{array}$ & Primary Regulation & Time of operation 0-30 sec. & No \\
& Secondary regulation & $\begin{array}{l}\text { Time of operation } 30 \mathrm{sec}-15 \\
\text { min (Spinning Reserve) }\end{array}$ & No \\
& Tertiary Regulation & $\begin{array}{l}\text { Response in 15 min and time } \\
\text { of operation of } 2 \text { hours (Stand } \\
\text { by reserve). }\end{array}$ & No
\end{tabular}

Even though the Spanish legislation only allows the consumers to participate in DAM and IDM, the current technology makes possible customers participation in the following short term markets:

1. Balancing markets (deviation management market in the Spanish case): Customers could obtain significant benefits by selling demand reductions through offers, due to the high prices in this market.

2. Ancillary Services. The tertiary regulation service will be one option for demand participation, like in the previous case.

\section{Simulation of participation in the Spanish markets}

This section is devoted to simulate and evaluate the potential of the UPV participation in BM and AS. Nevertheless, it is important to point out that buying the daily surplus of energy in advance is a necessary requirement. Energy can be bought in DAM and IDM markets or by using bilateral contracts with other agents. For this analysis, it has been selected one typical working day during the month of maximum consumption (July). 


\subsection{Participation in the daily and intra-daily markets}

The global strategy of participation resides on buying the energy in DAM with the DSBS performed by using the average daily consumption of every month. The energy unbalance is solved through the participation in the IDM.

The evolution in prices [18] in DAM during 2008 is shown in Figure 5. The maximum price for this year was about $0.10 € / \mathrm{kWh}$, and the minimum price for bid DPs was $0.50 € / \mathrm{kWh}$. According to these numbers, all the bids could be accepted in this market.

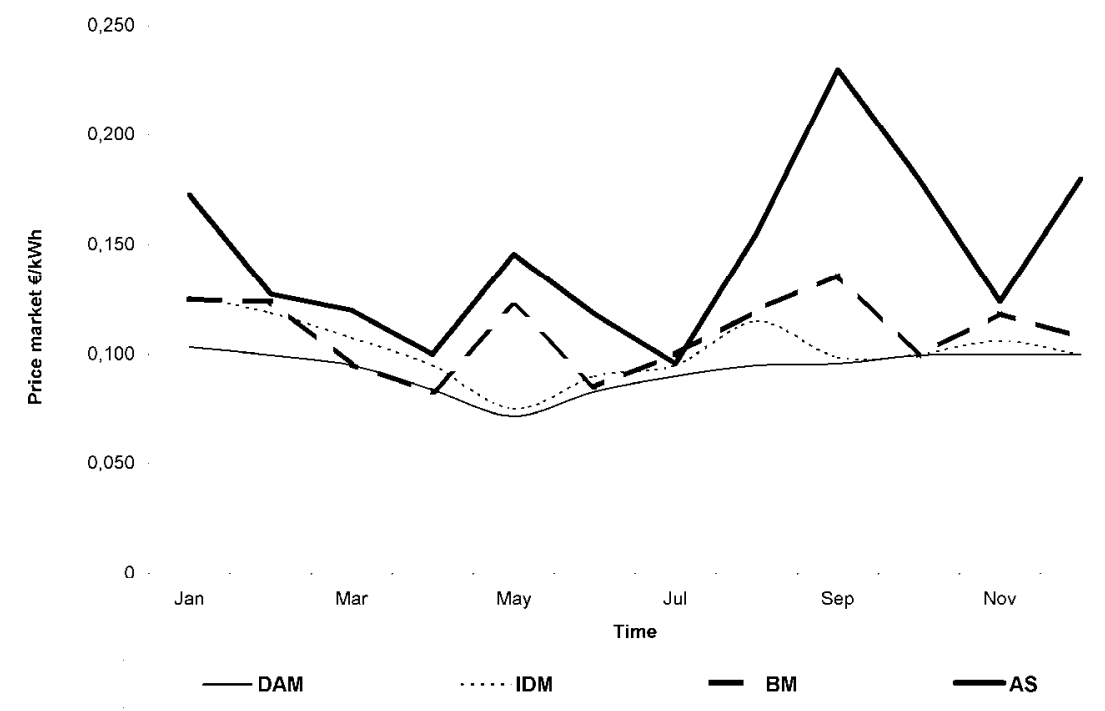

Figure 5. Price's evolutions of different Spanish markets in 2008

Differences in energy between the monthly average load curve and the consumption in a specific day are purchase in IDM.

The day of maximum consumption in 2008 was July $3^{\text {rd }}$. Figure 6 shows the monthly average curve used to buy in DAM, as well as the prices in this market. 


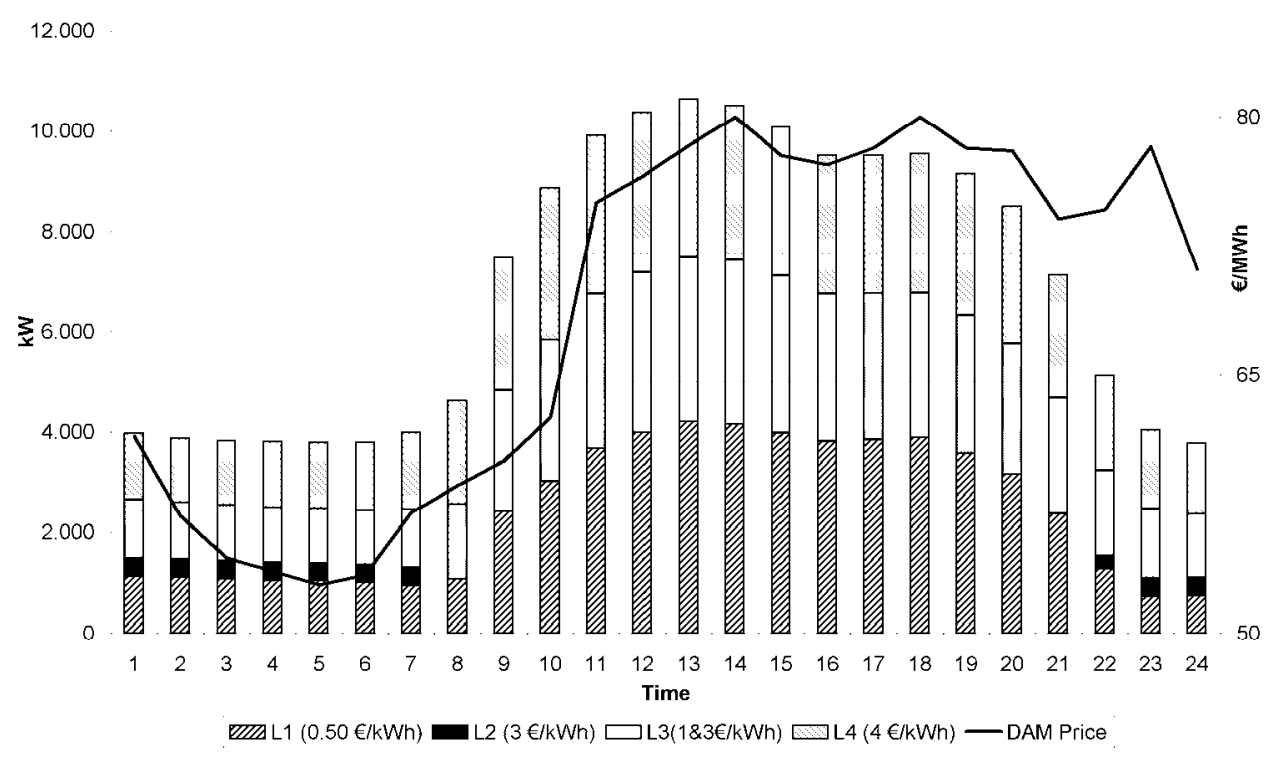

Figure 6. July's average monthly energy to buy in DAM and DAM price for July $3^{\text {rd }}$

The electricity price in all the IDM sessions was lower than 10 cent€/kWh, as it is shown in Figure 7.

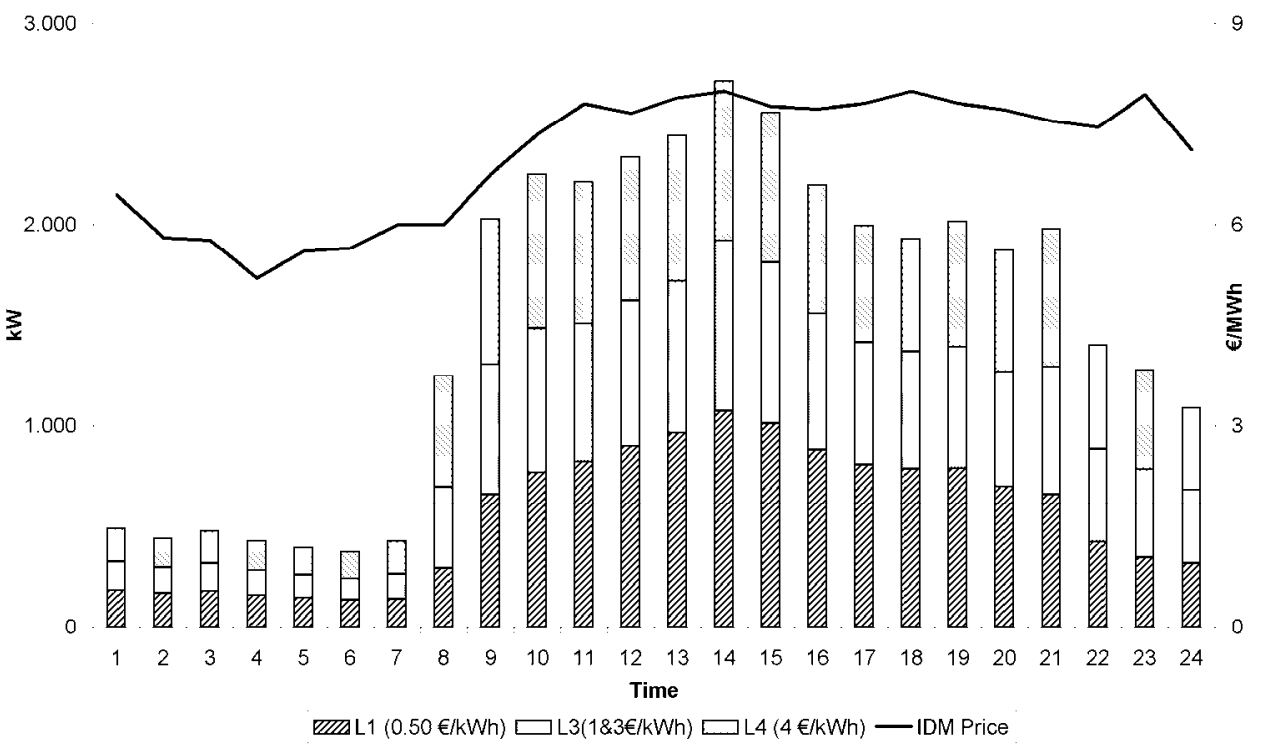

Figure 7. Participation in Intra-daily market for adjustments in July $3^{\text {rd }}$

\subsection{Participation in balancing markets and ancillary services}

After the expected consumption had been bought through a bidding process in the DAM and IDM, is possible to make offers for balancing markets and ancillary services.

In order to get the amount and price of DSOs to be offered in balancing markets for the rest of the year by using the results from January and July, as shown in Figure 4, it is only necessary to repeat the same methodology for the following months. 
According to these offers and prices during 2008 in BM and AS [19], some of the DSOs offered by UPV could have been accepted. Table 4 shows the chances to participate in this markets (the number of times that, at least, L1a offer could have been accepted, when the price was higher that $0.10 € / \mathrm{kWh}$ ). 
Table 4. Opportunity to participate in the BM and AS

\begin{tabular}{lcc}
\multirow{2}{*}{ Month } & \multicolumn{2}{c}{ Amount of chances } \\
& Balancing markets & Ancillary services \\
\hline January & 2 & 29 \\
February & 10 & 12 \\
March & - & 6 \\
May & - & 3 \\
June & - & 4 \\
July & 1 & - \\
August & 4 & 8 \\
September & 2 & 16 \\
October & - & 7 \\
November & - & 2 \\
December & - & 7 \\
\hline Total & 19 & 94
\end{tabular}

The number of opportunities to participate in BM and AS is limited for high offer prices, but the customer can obtain an effective response to events of low frequency with high price. For example, very dry months affect to the amount of hydraulic generation that means an increment in the price of these markets, just as it happened in $2002[20,21]$, when only in January the BM's price was 128 times higher than the DSO's price.

According to the information showed in Table 2, February $18^{\text {th }}$ was considered to evaluate the UPV participation in BM , as well as January $28^{\text {th }}$ for AS.

Market prices and energy offers for these days are shown in Figure 8. According to this figure, UPV offers would have been accepted in BM for 4 hours $(11-13,15-17)$ and for 6 hours $(8-12,18-20)$ in AS. The economic profits due to the implementation of those strategies could have been about $1.54 \mathrm{k} €$ in $\mathrm{BM}$ and 1.96k€ in AS. 


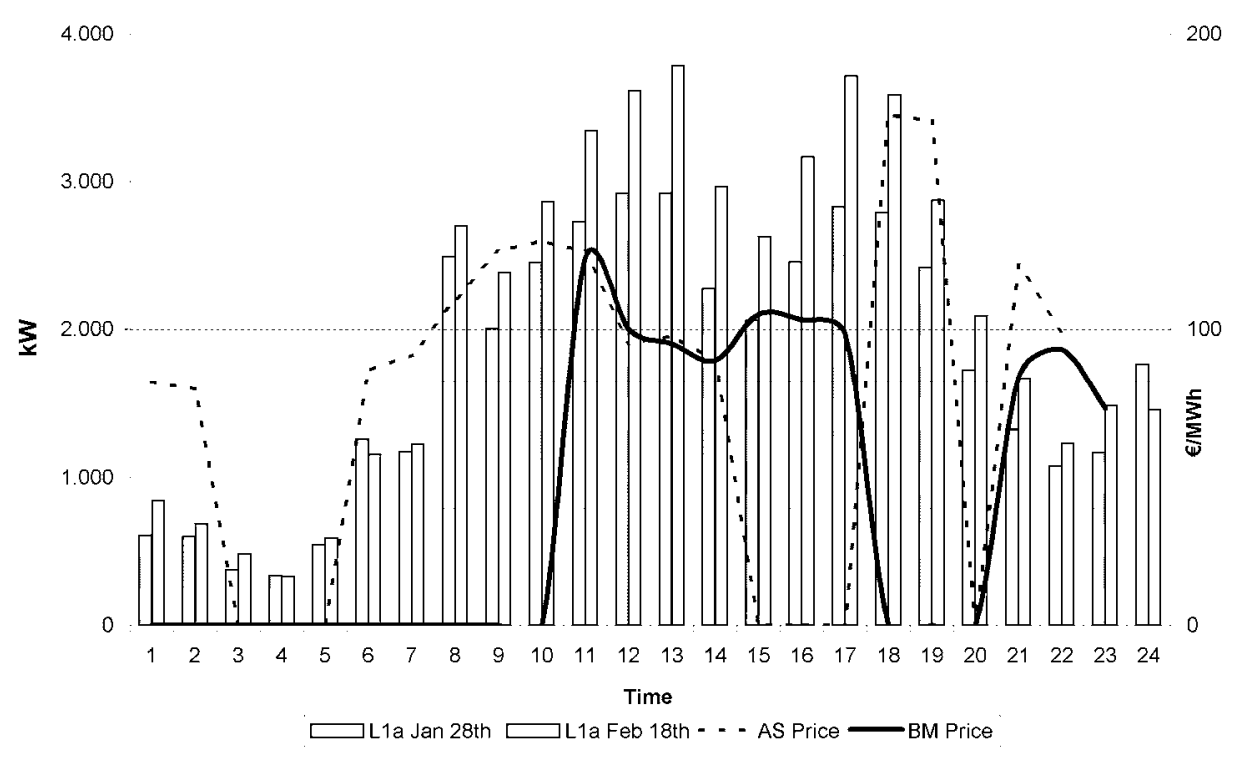

Figure 8. Participation in BM and AS

Market prices (BM and AS) in 2008 would have allowed the customer to sell only L1a DSO, except for the case of September when the AS price was greater than L1b price.

\section{Conclusions}

This paper presents the results of the simulation of a possible participation of customers in the Spanish electricity market by using their capability to reduce the electricity load when prices are high. Real data from the Universidad Politécnica de Valencia as an electricity customer with an energy management and control system was used for organizing its demand in packages and creating sets of hourly offers for over 24 hours trading periods. Real 2008 prices in the Spanish balancing and ancillary services markets were used in order to identify energy reductions to be offered by the customer and accepted in short term markets.

The case exposed in this paper proves that the participation of customers in short term markets could produce benefits for the customer while the efficiency of the electricity market is improved.

It is important to point out that the case presented in this paper is just an example applied to a specific customer for the Spanish case. Therefore even if results could seem not encouraging enough, it should be considered that they are masked by the fact that prices in the Spanish balancing market do not reflect the real costs of the balancing process. Hence the methodology 
applied to other countries or even just to other type of customer may produce even more encouraging results.

In summary, the paper proves that customers can obtain benefits from its active participation in electricity markets if a proper demand organization is used to create bids and offers.

\section{References}

[1] Rassanti, S., Smith, V. \& Wilson, B. Controlling Market Power and Price Spikes in Electricity Networks: Demand-Side Bidding. Interdisciplinary Center for Economic Science, George Mason University, July 2001.

[2] Sergio Bruno, Michele De Benedictis, Massimo La Scala, Ivar Wangensteen. Demand elasticity increase for reducing social welfare losses due to transfer capacity restriction: A test case on Italian cross-border imports. Electric Power Systems Research 76 (2006) 557-566

[3] D.S. Kirschen. Demand-side view of electricity markets. IEEE Trans. Power Systems, Vol. 18, May 2003, 520-527.

[4] GoranStrbac. Demand side management: Benefits and challenges. Energy Policy, No. 36 (2008) 4419-4426.

[5] AIE Task XIII. Market Barriers and Solutions. Available in:

http://62.121.14.21/ViewTask.aspx?ID=17\&Task=13\&Sort=1\#anc1168.

[6] P.O.-3.3 Resolución desvíos. Resolución de 25-2-1999 in BOE 09/03/99

[7] Y. Li, P.C. Flynn. Electricity deregulation, spot price patterns and demand-side management. Energy 31 (2006) 908-922

[8] Eric Hirst. Price-Responsive Demand in Wholesale Markets: Why Is So Little Happening? The Electricity Journal 2001.

[9] C. Álvarez, M. Alcazar, G. Escrivá, A. Gabaldón. Technical and economical tools to assess customer demand response in the commercial sector. Energy conversion and management, No. 50, pp. 2605-2612, 2009.

[10] NGC Procurement Guidelines. Available http://www.nationalgrid.com/uk

[11] The Nordic Power Market. Available: http://www.nordpool.com

[12] S. Braithwait, B. K. Eakin, L. D. Kirsch. Encouraging Demand Participation In Texas' Power Markets. August, 2002 
[13] L. E. Ruff. Economic Principles of Demand Response in Electricity. Available in:

http://www.eei.org

[14] C. A. Goldman, M. Kintner-Meyer, and G. Heffner. Do enabling technologies affect customer performance in price-responsive load programs?. Rep. LBNL-50328, Lawrence Berkeley National Laboratory. (2002, Aug.). Available: http://eetd.Ibl.gov/EA/EMP/.

[15] C. Alvarez, A. Gabaldon, A. Molina. Assessment and Simulation of the Responsive Demand Potential in End-User Facilities: Application to a University Customer. IEEE Trans. Power Syst., 19(2), 2004, 1223-1231.

[16] G. Escrivá, M. Alcázar, C. Álvarez. Integral Management System for the energy efficiency improvement in commercial facilities: Application to the Polytechnic University of Valencia. Proc. International Conference on Renewable Energies and Power Quality, April 2009. Available in http://www.derd.upv.es/

[17] C. Alvarez, R.P. Malhame, A. Gabaldon. A class of models for load management application and evaluation revisited. IEEE Trans. Power Syst., 7, 1992, 1435-1443.

[18] Operador del Mercado Ibérico de Energía - Polo Español. Available in http://www.omel.es/frames/es/resultados/resultados_index.htm [19] http://www.esios.ree.es/web-publica/

[20] Spanish electric system -Report 2002. Available in http://www.ree.es/apps/index_dinamico.asp?menu=/cap07/menu_sis.htm\&principal=/cap07/info rmeSEE.htm

[21] J.I: Pérez Arriaga. "Libro blanco sobre la reforma del marco regulatorio de la generación eléctrica en España", Ministerio de Industria, Turismo y Comercio, Madrid June 2005 available in http://www2.mityc.es/NR/rdonlyres/8123C43D-FDF8-4315-93EE-

9F608DBB7B71/0/LibroBlanco.pdf 